\title{
Decolorization and removal of toxicity of textile azo dyes using fungal biomass pelletized
}

\author{
E. J. R. Almeida ${ }^{1}$. C. R. Corso ${ }^{1}$
}

Received: 30 August 2017 / Revised: 8 December 2017 / Accepted: 9 May 2018 / Published online: 21 May 2018

(C) Islamic Azad University (IAU) 2018

\begin{abstract}
Industrialization and other human impacts have placed increasing pressure on aquatic environments, with the generation of large quantities of toxic aqueous effluents containing different substances, such as synthetic dyes and other organic pollutants. It is estimated that between 10 and $15 \%$ of all dyes used in textile processes and other industries are discharged into wastewater, causing extensive aquatic pollution. Biological methods have been employed for the removal of color and toxicity from effluents containing azo dyes. Therefore, biosorption tests were performed with the dyes Acid Blue 161 e Procion Red MX-5B in simple and binary solutions, whereas biodegradation treatment was performed with the dyes only in binary solution. For biosorption, the dyes were removed by the fungi Aspergillus niger, Aspergillus terreus and Rhizopus oligosporus. The fungal biomass demonstrated good adsorption capacity to these compounds. The elimination of the toxicity of the solution after biosorption demonstrated the effectiveness of the treatment. Intense molecular changes after biodegradation treatment with the A. terreus fungus were demonstrated by the FTIR analysis. However, toxicity tests with Lactuca sativa seeds and Artemia salina nauplii indicated the presence of highly toxic metabolites in the reaction medium at the end of the treatment. Based on the findings, biosorption is more suitable for this type of treatment, since it was also capable of removing the molecules from the medium, with the advantage of impeding the formation of highly toxic by-products.
\end{abstract}

Editorial responsibility: Xu Han.

Extended author information available on the last page of the article 


\section{Graphical abstract}

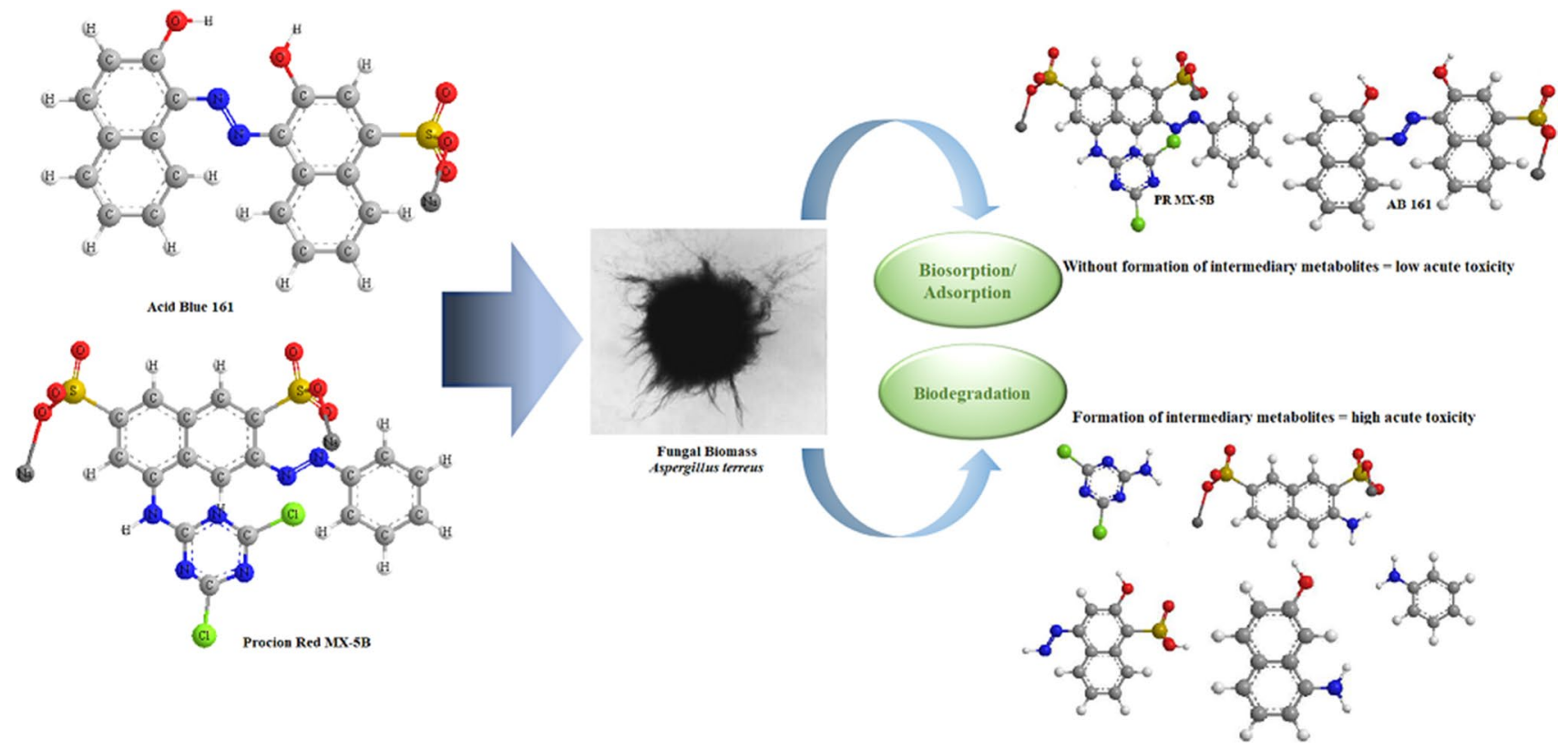

Keywords Artemia salina - Biological treatments $\cdot$ Filamentous fungi $\cdot$ Lactuca sativa $\cdot$ Synthetic dyes $\cdot$ Toxicity tests

\section{Introduction}

Industrialization and other human impacts have placed increasing pressure on aquatic environments, with the generation of large quantities of toxic aqueous effluents containing different substances, such as synthetic dyes and other organic pollutants (Fomina and Gadd 2014). The textile industry is the major consumer of synthetic dyes, which are an essential element in the dyeing process of fabrics. The main challenge facing this industry is the indiscriminate use of such compounds and the inefficiency of the dyeing process (Mahmoud et al. 2017). Indeed, textile manufacturers are among the largest consumers of water in industrial facilities, producing 50-100 $\mathrm{L}$ of wastewater per $\mathrm{kg}$ of finished product (Arslan-Alaton et al. 2008). Moreover, it is estimated that between 10 and $15 \%$ of all dyes used in textile processes and other industries are discharged into wastewater, causing extensive aquatic pollution (Edison et al. 2016).

About 100,000 different types of synthetic dyes and pigments are used on an industrial scale and approximately 700,000 tons are consumed per year. The most important group is azo dyes, which are characterized by the presence of one, two or three azo bonds $\left(\mathrm{R}_{1}-\mathrm{N}=\mathrm{N}-\mathrm{R}_{2}\right)$. These dyes account for $60-70 \%$ of all synthetic dyes produced worldwide (Konicki et al. 2017; Wang et al. 2017a, b) and constitute a potential hazard to aquatic environments and human health. When improperly discarded into aquatic ecosystems, effluents containing these substances can cause serious disturbances, such as a reduction in the water solubility of oxygen and adverse effects due to the toxicity, mutagenicity and carcinogenicity of their molecules and/ or their intermediates (Mittal et al. 2013; Chequer et al. 2015; Song et al. 2017). Considering an important class of environmental pollutants, azo dyes are resistant to many types of treatment, difficult to mineralize and persistent in aquatic environments due to their bio-recalcitrance.

Physical, chemical and biological methods have been employed for the removal of color and toxicity from effluents containing azo dyes, such as coagulation-flocculation (Lau et al. 2014), advanced oxidation processes (Abdi et al. 2017), biodegradation (Song et al. 2017) and adsorption/biosorption (Guerrero-Coronilla et al. 2015). With biological treatments, the mechanism of decolorization occurs through biosorption, enzymatic degradation (biodegradation) or a combination of both.

The advantage of biosorption/adsorption is that the process occurs without the formation of metabolites. Biological materials, such as chitin, chitosan, peat, yeast and fungi biomass, are used as chelating and complexing sorbents to concentrate and remove dyes from a solution. These biosorbents and their derivatives contain a variety of functional groups that can form complexes with dyes through physicochemical interactions. However, the efficiency and 
selectivity of adsorption by biomass is mainly due to ion exchange mechanisms (Crini et al. 2006).

The biodegradation process occurs with the formation of intermediates (metabolites), which are often more toxic than the parent dye. Therefore, it is important for any bioremediation technology to assess the toxicity of the pollutants and metabolites formed after dye degradation to determine the efficiency of the method (Sen et al. 2016).

The aim of the present study, performed in the Bioscience Institute, Biochemistry and Microbiology Department, São Paulo State University, Rio Claro, São Paulo (2012-2013) was to analyze the use of adsorption and biodegradation methods for the treatment of the azo dyes Procion Red MX-5B and Acid Blue 161 in aqueous solutions employing pelletized biomasses of the filamentous fungi Aspergillus niger, Aspergillus terreus and Rhizopus oligosporus. Acute toxicity of the solutions before and after treatments was analyzed using Lactuca sativa seeds and Artemia salina nauplii.

\section{Materials and methods}

\section{Azo dyes}

The azo dyes Acid Blue 161 (AB 161) and Procion Red MX-5B (PR MX-5B) were analyzed in simple and binary solutions (Fig. 1). The main characteristics of these dyes are:

AB 161 (EC Number: 235-628-6) was acquired from the Sigma-Aldrich Inc. (São Paulo, Brazil) and has the following characteristics: molecular weight: 394.40 ; water soluble; $\lambda_{\max }=602 \mathrm{~nm}$; and dye content: $\sim 45 \%$.

And the PR MX-5B (EC Number: 241-776-2) was acquired from I.C.I. Brazil Inc. (Rio Claro, São Paulo, Brazil) and has the following characteristics: molecular weight: 615.33; water soluble; $\lambda_{\max }=538 \mathrm{~nm}$; and dye content: $\sim 40 \%$.

\section{Microorganisms}

Decolorization tests were performed with the filamentous fungi A. niger (CCT 1435), A. terreus (CCT 2679) and $R$. oligosporus (CCT 3762) obtained from the culture collection of the André Tosello Foundation for Research and Technology. The fungi were used in their paramorphogenic physical form (Marcanti-Contato et al. 1997).

\section{Toxicity tests}

Toxicity tests were performed with the brine shrimp $A$. salina and $L$. sativa seeds. The test with $A$. salina was based on the mortality of nauplii after $48 \mathrm{~h}$ of exposure to the PR MX-5B and AB 161 dyes in simple and binary solutions. The test was conducted in test tubes containing dye solution at different concentrations and 10 A. salina nauplii before and after decolorization treatments with the filamentous fungi.

The lethal concentration $\left(50 \%\right.$ mortality rate $\left.\left(\mathrm{LC}_{50}\right)\right)$ of the dye solutions was determined using the trimmed Spearman-Karber method (Hamilton et al. 1977). The test
Fig. 1 UV-Vis spectra of dyes AB 161 and PR MX-5B in simple and binary solutions

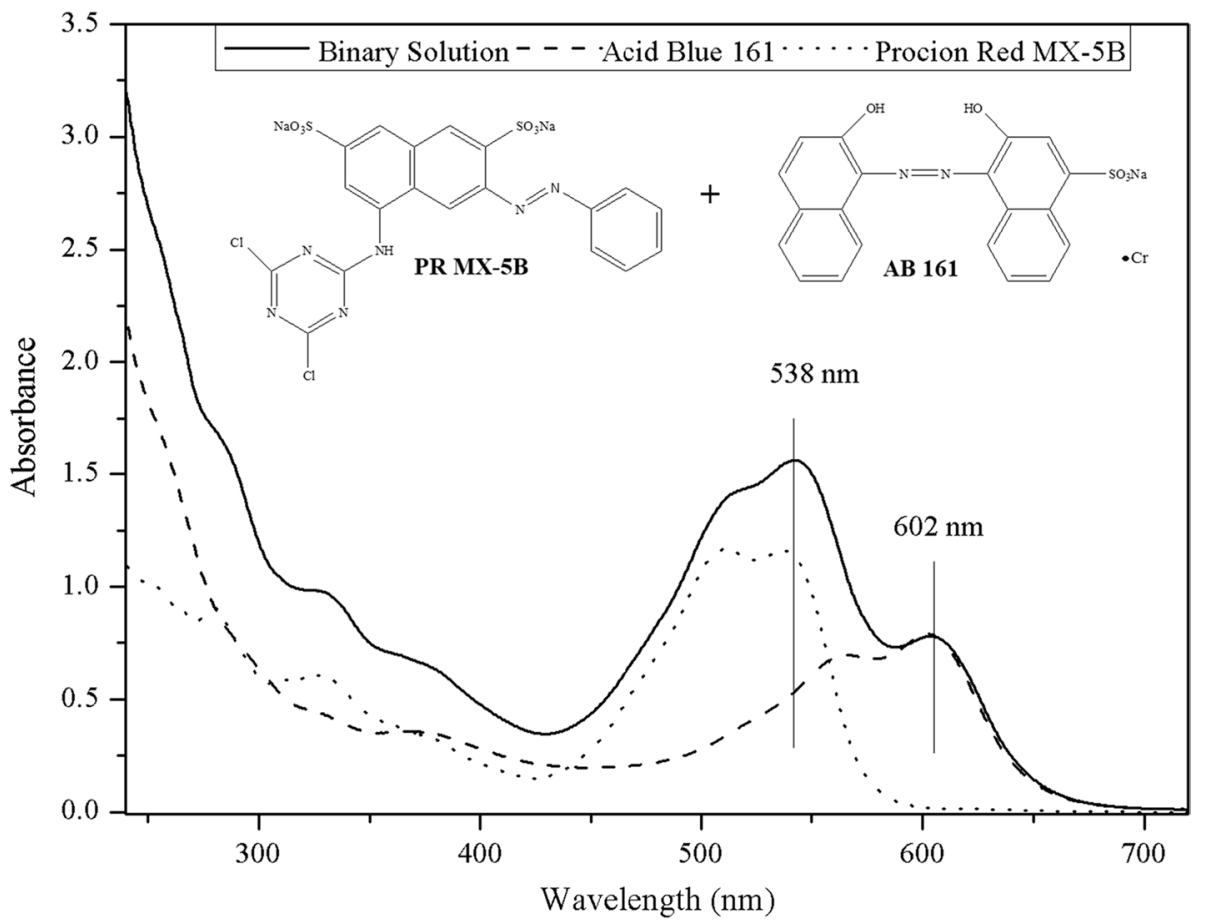

Springer 
is considered valid when the survival rate in artificial seawater ( $\mathrm{pH} \mathrm{8}$, salinity: $3.2 \%$ ) is equal to or greater than $90 \%$ and the $\mathrm{LC}_{50}$ for sodium dodecyl sulfate (SDS) is within the sensitivity range of $13.95-20.23 \mathrm{mg} \mathrm{L}^{-1}$. The sensitivity determined in the present study was $19.30 \mathrm{mg} \mathrm{L}^{-1}$ (Platte et al. 2002), demonstrating that the test was considered valid.

For the toxicity test with L. sativa (TopSeed ${ }^{\circledR}$ Garden), the first aim was to determine the inhibition of root growth of the seeds before the adsorption and biodegradation treatments to determine the $\mathrm{LC}_{50}$ of each dye studied in the simple and binary solutions. The test was conducted in Petri dishes with filter paper, 20 seeds and $3 \mathrm{~mL}$ of the test solution in a climatic chamber at $21 \pm 1^{\circ} \mathrm{C}$ in the absence light for $72 \mathrm{~h}$. The positive control was $\mathrm{ZnSO}_{4} 0.05 \mathrm{~N}$ and the negative control was distilled water. After this period, measurements of the roots were taken and growth inhibition (GI) is calculated using Eq. (1). terreus and $R$. oligosporus), the Freundlich and Langmuir isotherms were applied. The isotherms proposed by Wang et al. (2017a, b) are employed using Eqs. (2) and (3).

Freundlich isotherm equation

$\log q e=\log K+\frac{1}{n} \cdot \log D r$

in which $q e=$ concentration of adsorbed per unit of biomass $\left(\mathrm{mg} \mathrm{g}^{-1}\right) ; D r=$ dye remaining $\left(\mathrm{mg} \mathrm{mL}^{-1}\right) ; \log K$ is the $y$ intercept; and $n$ is the slope.

Langmuir isotherm equation

$\frac{D r}{q e}=\frac{1}{K 1 \cdot K 2}+\frac{D r}{K 2}$

in which $K 1=$ is the $y$ intercept and $K 2=$ amount of solute that saturates a unit of biomass with a monolayer adsorbent $\left(\mathrm{mg} \mathrm{mL} \mathrm{L}^{-1}\right)$.

The sorption capacity of mycelial pellets of fungi tested

$\mathrm{GI}(\%)=\frac{(\text { root growth negative control }- \text { root growth dye solution })}{(\text { root growth negative control })} \times 100$

\section{Adsorption treatment}

Adsorption was performed with $10 \mathrm{~mL}$ of each dye solution at a concentration of $100 \mu \mathrm{g} \mathrm{mL}^{-1}$ and $\mathrm{pH} 4.0$ for the PR MX-5B and AB 161 dyes in simple solutions. For the binary solution, the concentration was of $200 \mu \mathrm{g} \mathrm{mL}^{-1}$ $\left(100 \mu \mathrm{g} \mathrm{mL}^{-1}\right.$ AB $161+100 \mu \mathrm{g} \mathrm{mL}^{-1}$ PR MX-5B). The solutions were placed in contact with $1,2,3,4$ and $5 \mathrm{mg} \mathrm{mL}{ }^{-1}$ of pelletized biomass of each fungus tested for $3 \mathrm{~h}$ at a temperature of $30 \pm 1^{\circ} \mathrm{C}$. The values specified for time, $\mathrm{pH}$ and initial concentration were selected based on data obtained from previous studies.

Decolorization of the solutions was monitored using UV-Vis spectrophotometry (Shimadzu UV-Vis 2401 PC). After the period of contact between the adsorbent biomass and dye, the solutions were centrifuged at $5000 \mathrm{rpm}$ for $10 \mathrm{~min}$. The rate of decolorization was calculated from the results of absorbance at $\lambda_{\max }=602$ (AB 161) and 538 (PR MX-5B) nm. The UV-Vis scans were performed using a quartz cuvette with an optical path of $5 \mathrm{~mm}$.

\section{Adsorption isotherms and adsorption capacity of mycelial pellets}

Adsorption isotherms are important to describing interactions between adsorbate molecules and the biosorbent surface as well as distribution between the liquid and solid phases in a state of equilibrium (Rosales et al. 2016). After the adsorption test with the filamentous fungi (A. niger, $A$. is calculated using Eq. (4) proposed by Asgher and Bhatti (2010).

$q=\frac{(D i-D e) \cdot V}{W}$

in which $q=$ amount of dye adsorbed per unit of adsorbent biomass $\left(\mathrm{mg} \mathrm{g}^{-1}\right), D i$ and $D e=$ initial and final concentrations of dyes $\left(\mathrm{mg} \mathrm{mL}^{-1}\right), v=$ volume of solution tested $(\mathrm{mL})$ and $W=$ amount of adsorbent biomass (g).

\section{Biodegradation treatments}

Biodegradation treatments were performed with the PR MX-5B and AB 161 dyes in binary solutions and using the fungus $A$. terreus, based on findings in other biodegradation studies. Biodegradation was performed with the 3 - $\mathrm{mg} \mathrm{mL}^{-1}$ of A. terreus biomass in 100-mL Erlenmeyer flasks containing $25 \mathrm{~mL}$ of binary solution at a concentration of $200 \mu \mathrm{g} \mathrm{mL}^{-1}$ and sterilized by autoclaving at $120^{\circ}$ $\mathrm{C}$ and $1 \mathrm{~atm}$ for $15 \mathrm{~min}$. The flasks were then incubated at $30 \pm 1{ }^{\circ} \mathrm{C}$. The solutions were analyzed at intervals of 24,240 and $336 \mathrm{~h}$ of treatment. For the UV-Vis, FTIR (Shimadzu-8300) and toxicity analysis, the solutions were centrifuged at $5000 \mathrm{rpm}$ for $10 \mathrm{~min}$. Changes in the UV-Vis spectra of each dye before and during treatment enabled evaluating the degradation of the molecules

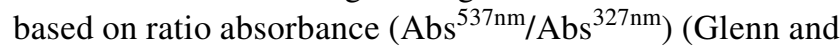
Gold, 1983). After treatment, FTIR analysis was performed using the method proposed by Vitor and Corso 
(2008) for the determination of the molecular structure of the dyes in the binary solution.

\section{Results and discussion}

\section{Determination of $\mathrm{LC}_{50}$}

Among environmental factors, water availability and quality influence the germination and development of plants. The absorption of water by seeds causes the hydration of tissues, leading to the intensification of respiration and all other metabolic activities, which result in the supply of energy and nutrients for the development of the embryonic axis (Palácio et al. 2009). Therefore, the $\mathrm{LC}_{50}$ (Fig. 2, graph A) of the PR MX-5B and AB 161 dyes in simple and binary solutions was determined in the first stage of the experiment.

The AB 161 dye was more toxic, as demonstrated by the 1.5 -fold lower $\mathrm{LC}_{50}$ in comparison with the PR MX-5B. In the binary solution, the $\mathrm{LC}_{50}$ was $1400 \mu \mathrm{g} \mathrm{mL}^{-1}$ of each of the dyes, indicating that the combination did not make the solution more toxic to $L$. sativa seeds.

The nauplii of the microcrustacean A. salina are considered a good indicator of the presence of toxic substances in the aquatic environment and are easy to handle in the laboratory, providing fast, reliable results (Liwarska-Bizukojc et al. 2005). The results enabled the calculation of $\mathrm{LC}_{50}$ (Fig. 2, graph B) values for each solution, which were $2175 \mu \mathrm{g} \mathrm{mL}^{-1}$ for $\mathrm{AB} 161,2570 \mu \mathrm{g} \mathrm{mL}^{-1}$ for PR MX-5B and $2600 \mu \mathrm{g} \mathrm{mL}^{-1}$ for the binary solution.

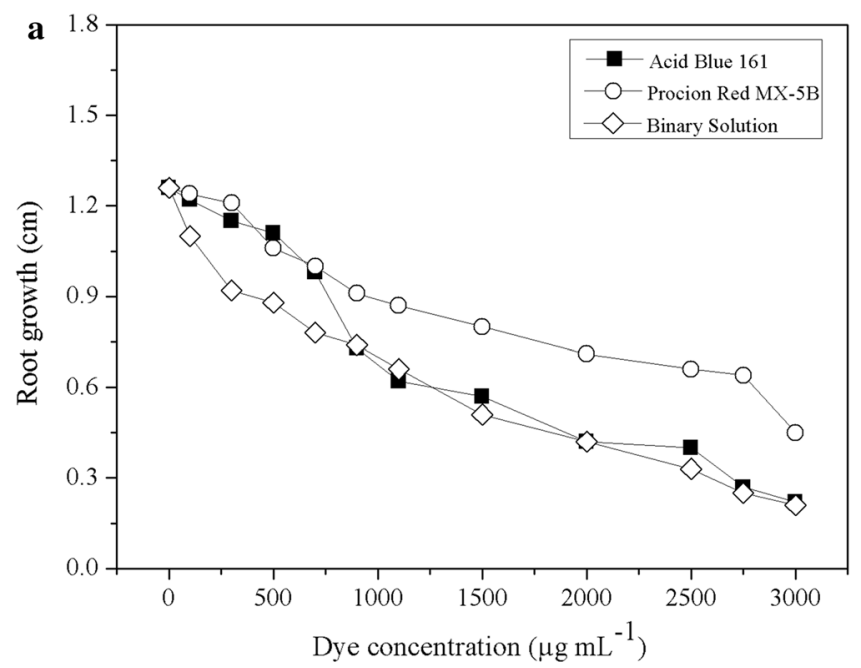

\section{Adsorption treatments: decolorization, adsorption capacity of mycelial pellets, isotherms and toxicity tests}

The decolorization rate was proportional to the amount of fungal biomass (Fig. 3, graphs 1a, 2a and 3a) used in each treatment, with an increase in biomass leading to an increase in decolorization. The fungus $A$. niger achieved the highest removal rates of the PR MX-5B and AB 161 dyes in the simple and binary solutions. AB 161 was more easily removed from the reaction medium by the three filamentous fungi studied, indicating that this dye has greater affinity with the cell walls of these microorganisms.

The fungal cell wall consists mainly of polysaccharides, proteins, lipids and several functional groups. Dyes may interact with these active groups on the cell wall surface through physical (Van der Waals forces) or chemical (ion exchange or covalent bond) mechanisms (Crini 2006).

Kabbout and Taha (2014) studied the decolorization of the cationic dye methylene blue by a dead fungal biomass of Aspergillus fumigatus. Using $5 \mathrm{~g}$ of biomass, the results revealed rapid adsorption, with a rate decolorization of $58 \%$ in 30 min and 68\% in 120 min. Peak adsorption (71\%) occurred at $210 \mathrm{~min}$. In the present investigation using the same amount of live biomass, maximum decolorization in the treatment of the binary solution by A. niger occurred after $180 \mathrm{~min}$. The greater efficiency of dead fungal biomass regarding the decolorization of the solutions is likely due to the fact that dead biomass does not present any resistance to the adsorption process of the dyes.

Regarding the adsorption capacity (Fig. 3, graphs $1 b, 2 b$ and $3 b$ ), the biosorbent pellets present as a tangled mass of hyphae surrounded by many loose hyphae on the surface

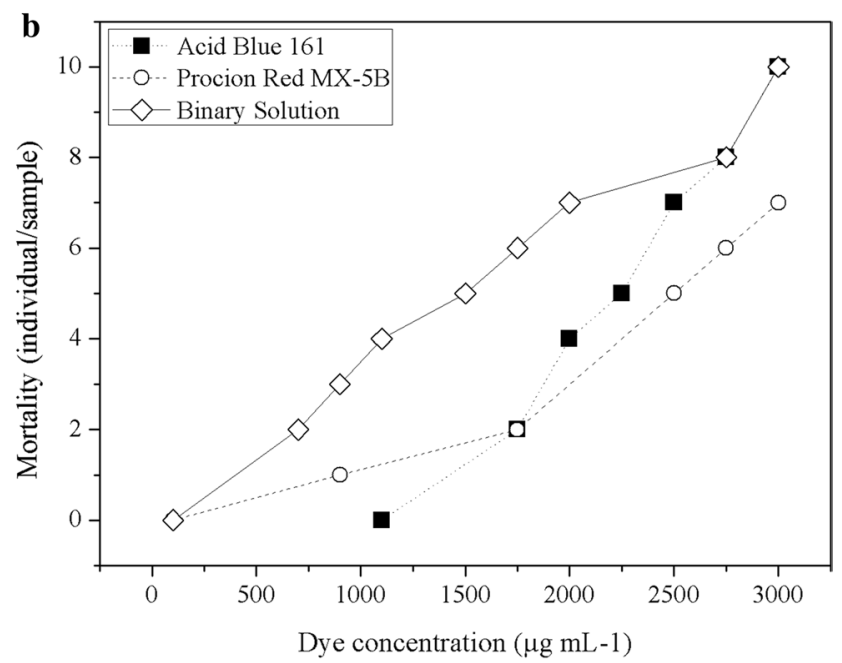

Fig. 2 a Inhibition of root growth of $L$. sativa seeds and $\mathbf{b}$ mortality of A. salina nauplii exposed to different concentrations of $\mathrm{AB} 161$, PR MX-5B and binary solution 

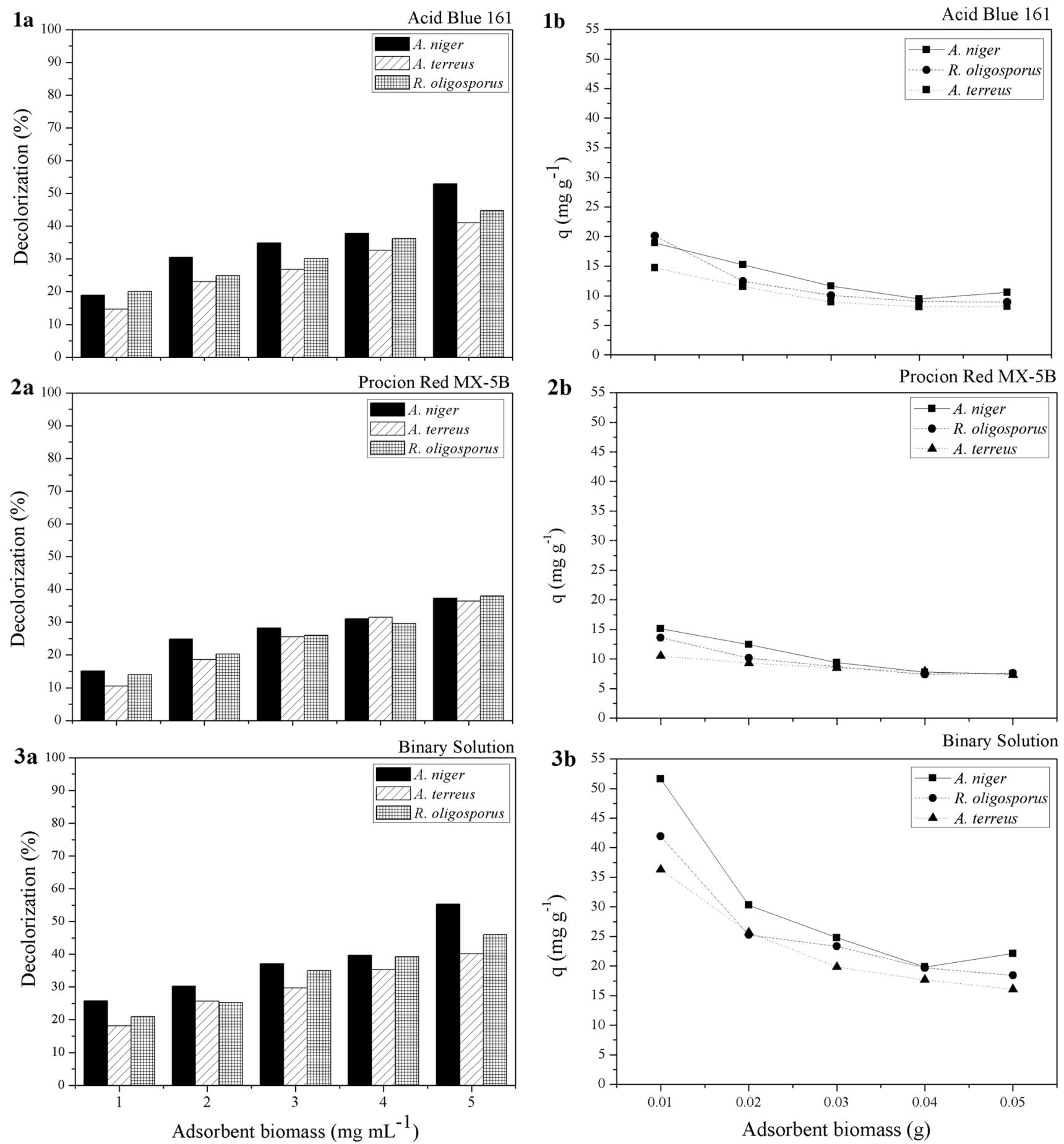

Fig. 3 Decolorization and adsorption capacity of mycelial pellets after $3 \mathrm{~h}$ of adsorption treatments. (1a, 1b) AB 161, (2a, 2b) PR MX-5B and $(\mathbf{3 a}, \mathbf{3 b})$ binary solution

(Fig. 4, image 1). This conformation enables the adherence of dye molecules, which explains why an increase in quantity of pellets in the solutions tested led to a reduction in the sorption capacity of the biomass. Compaction of mycelium occurs in the presence of a greater amount of biomass, reducing the contact surface of the biomass with the dye molecules.
Therefore, although decolorization was greater in solutions with a larger amount of biomass, each pellet used in the adsorption process was less efficient under these conditions.

The Freundlich and Langmuir isotherms were applied to evaluate how the interaction between the adsorbent substrates and dyes occurred. In the Langmuir isotherm, all 
Fig. 41 Fungal pellets $(a) A$. niger, (b) R.oligosporus and (c) A. terreus after adsorption process in binary solution; 2 Adsorption scheme of dyes through cell wall of pelletized fungal biomass. (a) AB 161, (b) PR MX-5B and (c) binary solution

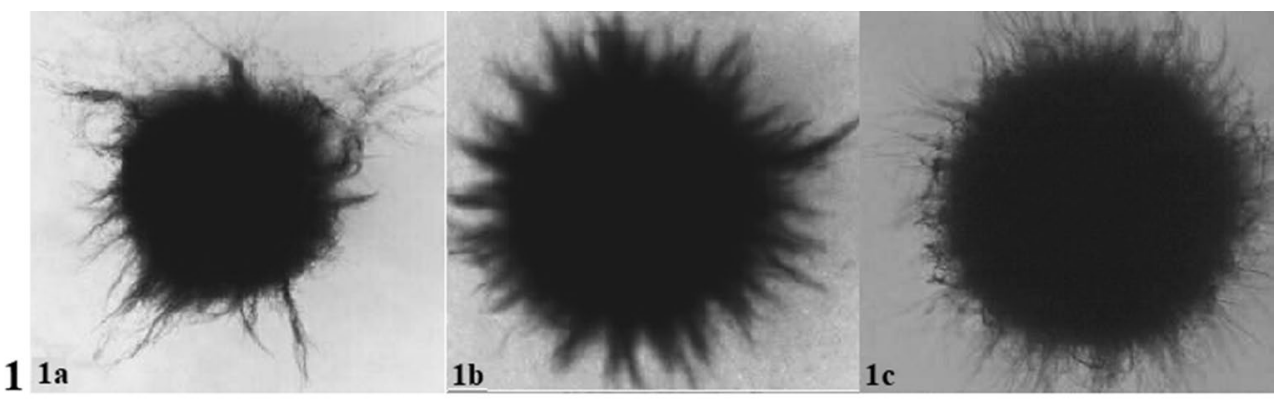

$\underline{1 b}$

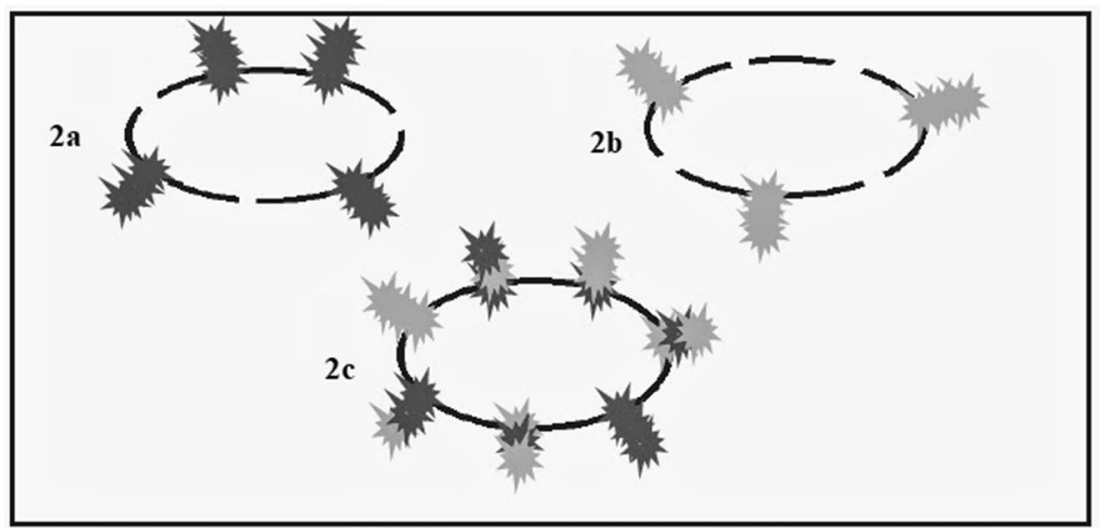

Table 1 Correlation coefficients of Freundlich and Langmuir equations

\begin{tabular}{|c|c|c|c|c|c|}
\hline \multicolumn{2}{|c|}{ Acid blue 161} & \multicolumn{2}{|c|}{ Procion red MX-5B } & \multicolumn{2}{|c|}{ Binary solution } \\
\hline $\begin{array}{l}\text { Freun- } \\
\text { dlich }\end{array}$ & Langmuir & $\begin{array}{l}\text { Freun- } \\
\text { dlich }\end{array}$ & Langmuir & $\begin{array}{l}\text { Freun- } \\
\text { dlich }\end{array}$ & Langmuir \\
\hline \multicolumn{6}{|l|}{ A. niger } \\
\hline 0.5073 & 0.2947 & 0.8650 & 0.6642 & 0.3015 & 0.2516 \\
\hline \multicolumn{6}{|c|}{ A. terreus } \\
\hline 0.7399 & 0.1489 & 0.9937 & 0.0322 & 0.9078 & 0.8503 \\
\hline \multicolumn{6}{|c|}{ R. oligosporus } \\
\hline 0.5869 & 0.1769 & 0.7309 & 0.2788 & 0.7053 & 0.2741 \\
\hline
\end{tabular}

forces acting on adsorption are similar in nature to those involving a chemical reaction and adsorption occurs in a single layer of dye molecules on the surface of the adsorbent. In the Freundlich isotherm, adsorption occurs in multiple layers; this isotherm is useful for describing adsorption on highly heterogeneous surfaces. The isotherms were analyzed from their correlation coefficients $\left(R^{2}\right)$ (Table 1) obtained from the analysis of the results of the adsorption test.

Analyzing the correlation coefficients, the adsorption with the pelletized fungal biomass occurred in accordance with the Freundlich isotherm, that is, the removal of the dyes occurred through multiple layers. This adsorption model explains the decolorization results, which indicate that the dye removal rate was smaller in the simple solution than the binary solution. This suggests the presence of specific active sites (Fig. 4, image 2) for each of the dyes. In the binary solution, all available fixation sites on the surface of the pellets were filled, thereby increasing the adsorption capacity of the pellets and consequently increasing the decolorization rate in the binary solution. Moreover, no toxicity to A. salina nauplii or L. sativa seeds was found after the adsorption process with the filamentous fungi A. terreus, A. niger and R. oligosporus.

\section{Binary solution: biodegradation treatments with $A$. terreus}

Biodegradation of the binary solution was performed with the fungus A. terreus (Fig. 5, graph A). After 24 h of treatment, the fungal biomass presented greater affinity for AB 161, removing 84\% of the dye. Moreover, decolorization remained constant until the end of treatment. For PR MX-5B, $40 \%$ of decolorization occurred in $24 \mathrm{~h}$ of treatment, totaling $60 \%$ decolorization of the binary solution. At 240 and $336 \mathrm{~h}$ of treatment, this dye was completely removed. At the end of the treatments, $92 \%$ decolorization of the initial solutions was obtained.

The absorbance ratios were calculated from the UV-Vis analyzes of the solutions. According to Glen and Gold (1983), adsorption is the predominant process if these values remain constant in relation to the control solution and biodegradation of the molecules is indicated when these values exhibit significant changes. Analyzing the results, it's possible to observe (Fig. 5, graph B) a significant variation in the absorbance ratios of the solution occurred in the first 

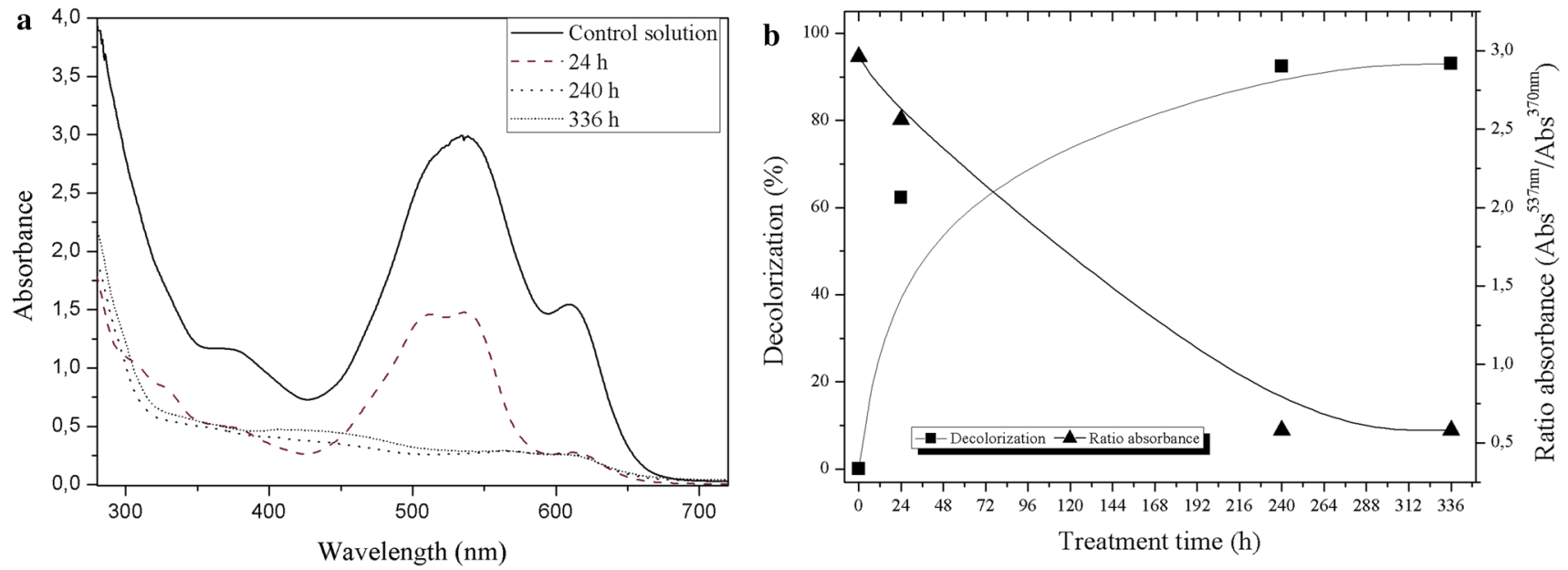

Fig. 5 a Decolorization and $\mathbf{b}$ ratio absorbance of binary solution after treatment with $A$. terreus
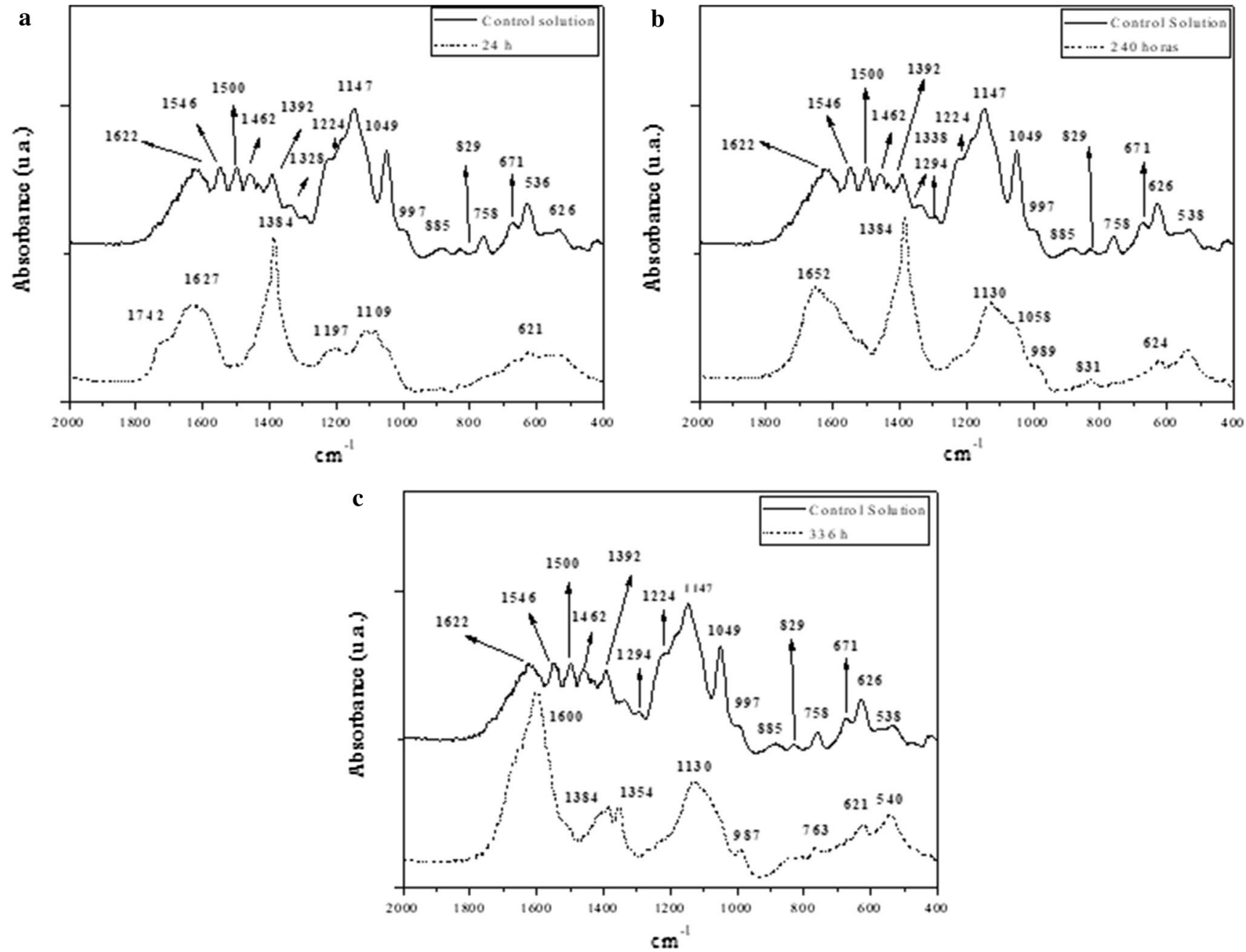

Fig. 6 FTIR spectra of binary solution before and after biodegradation treatments 

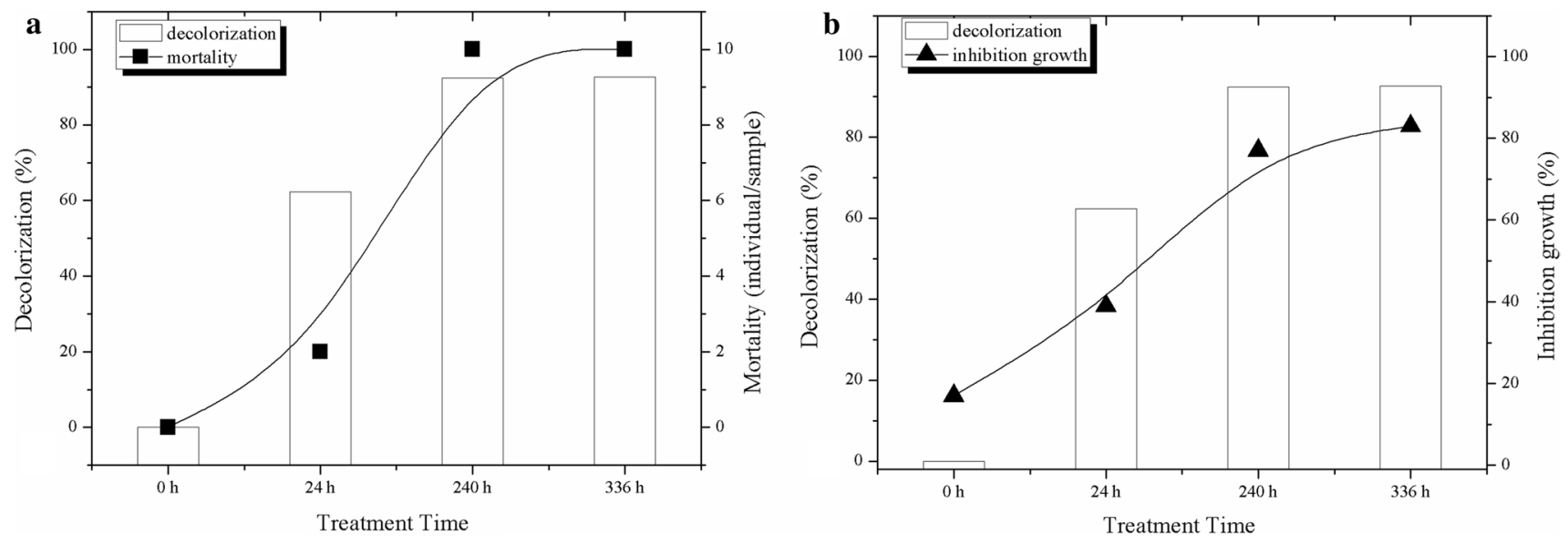

Fig. 7 a Mortality of A. salina nauplii after biodegradation treatment with A. terreus; b Growth inhibition of L. sativa seeds after biodegradation treatment with A. terreus

$24 \mathrm{~h}$ of treatment, indicating high microbial activity and the consequent degradation of dye molecules.

The FTIR spectra of the binary solution exhibited significant changes after the biological treatment (Fig. 6). In all treatments, spectral changes occurred in the regions of 1622 , $1500-1550$ and $1462 \mathrm{~cm}^{-1}$, which are characteristics of azo bonds and stretching vibration of the $\mathrm{C}-\mathrm{N}$ bond (Gao et al. 2010). These changes indicate the breakage of these bonds, leading to the formation of aromatic amino compounds as intermediates. The formation of these metabolites suggests that some peaks corresponding to vibrations of the $\mathrm{NH}_{2}$ bond of aromatic amines appear more intensely after contact with the fungal biomass. These peaks can be observed in the region of $1109 \mathrm{~cm}^{-1}$ at $24 \mathrm{~h}, 1678 \mathrm{~cm}^{-1}$ at $240 \mathrm{~h}$ and $1600 \mathrm{~cm}^{-1}$ at $336 \mathrm{~h}$ of treatment (Pacchade et al. 2009; Olukanni et al. 2010).

The peak that appears in the region of $1742 \mathrm{~cm}^{-1}$ at $24 \mathrm{~h}$ of treatment is characteristic of the change in the $\mathrm{C}=\mathrm{O}$ stretching band of the carboxyl group (Zhang et al. 2017). This peak disappears at 240 and $336 \mathrm{~h}$, which indicates complete breakage of these chemical bonds during biodegradation treatment. The 987 and $540 \mathrm{~cm}^{-1}$ regions correspond to aromatic compounds and the changes having occurred after treatment indicate cleavage of the chemical bonds of these functional groups.

At 24,240 and $336 \mathrm{~h}$ of treatment, bands appeared in the regions of 1384, 1354, 624 and $621 \mathrm{~cm}^{-1}$, indicating the presence of sulfonic groups (Rawat et al. 2018; Harisha et al. 2017). Sulfonated radicals are found in both dyes, and the enzymatic action on the molecules may have led to the cleavage of the bonds of these groups, releasing them into the reaction medium, which generated an increase in the intensity of the signals of these bands.

The results of the toxicity tests for A. salina nauplii and L. sativa seeds (Fig. 7) showed a $100 \%$ mortality rate of the larvae occurred at the end of the $336 \mathrm{~h}$ of degradation treatment. The final solution after the treatment contained residual $\mathrm{AB} 161$ dye and metabolites formed during the biodegradation steps. These metabolites were responsible for the increase in larval mortality.

The microbiological treatment of the binary solution also led to increased inhibition of root growth of $L$. sativa seedlings. The percentage of root growth inhibition increased from $17 \%$ (toxicity control binary solution) to $83 \%$ at the end of $336 \mathrm{~h}$ of treatment.

\section{Conclusion}

Analyzing the findings, the more efficient treatment was biosorption with the pelletized biomasses of the fungi A. terreus, A. niger and $R$. oligosporus. The fungal biomass was able to remove the dye from the medium without degrading the molecules, which was very favorable due to the non-formation of highly toxic by-products. In the biosorption treatment, each dye bounds to specific active sites on the fungal cell walls, as demonstrated by the greater removal of these molecules in the binary solution, indicating more efficient treatment due to the filling of all active sites. The high rate of decolorization obtained during treatment confirmed dye removal by biosorption in multiple layers. While the biodegradation treatment was quite efficient in achieving decolorization, the formation of by-products with high toxicological potential reduces the usefulness of the method. Biodegradation treatments with longer exposure times may be more efficient, since greater exposure to microorganisms enables the complete degradation and consequent mineralization of these metabolites, which are highly persistent in the environment and cause considerable harm to aquatic fauna and flora.

Acknowledgements Our research group acknowledges CAPES (Coordenação de Aperfeiçoamento de Pessoal de Nível Superior), 
FAPESP (Fundação de Amparo à Pesquisa do Estado de São Paulo), CNPq (Conselho Nacional de Desenvolvimento Científico e Tecnológico), FUNDUNESP (Fundação para o Desenvolvimento da UNESP) and UNESP (Universidade Estadual Paulista "Júlio de Mesquita Filho") for the financial support.

\section{References}

Abdi P, Farzi A, Karimi A (2017) Application of a hybrid enzymatic and photo-fenton process for investigation of azo dye decolorization on $\mathrm{TiO}_{2}$ /metal-foam catalyst. J Taiwan Inst Chem Eng 71:137-144

Arslan-Alaton I, Gursoy BH, Schmidt JE (2008) Advanced oxidation of acid and reactive dyes: effect of Fenton treatment on aerobic, anoxic and anaerobic processes. Dyes Pigments 78:117-130

Asgher M, Bhatti HN (2010) Mechanistic and kinetic evaluation of biosorption azo dyes by free, immobilized and chemically treated Citrus sinensis waste biomass. Ecol Eng 36:1660-1665

Chequer FMD, Lizier TM, Felício F, Zanoni MVB, Debonsi HM, Lopes NP, Oliveira DP (2015) The azo Disperse Red 13 and its oxidation and reduction products showed mutagenic potential. Toxicol Vitro 29:1906-1915

Crini G (2006) Non-conventional low-cost adsorbents for dye removal: a review. Bioresour Technol 97:1061-1085

Edison TNJI, Atchudan R, Sethuraman MG, Lee RY (2016) Reductivedegradation of carcinogenic azo dyes using Anacardium occidentale testa derived silver nanoparticles. J Photochem Photobiol B Biol 162:604-610

Fomina M, Gadd GM (2014) Biosorption: current perspectives on concept, definition and application. Bioresour Technol 160:3-14

Gao JF, Zhang Q, Su K, Wang JH (2010) Competitive biosorption of Yellow $2 \mathrm{G}$ and Reactive Brilliant Red K-2G onto inactive aerobic granules: simultaneous determination of two dyes by first-order derivate spectrophotometry and isotherm studies. Bioresour Technol 101:5793-5801

Glenn JK, Gold MH (1983) Decolorization of several polymeric dyes by the Lignin Degrading basidiomycete Phanerochaete chrysosporium. Appl Environ Microbiol 45:1741-1747

Guerrero-Coronilla I, Morales-Barrera L, Cristiani-Urbina E (2015) Kinetic, isotherm and thermodynamic studies of amaranth dye biosorption from aqueous solution onto water hyacinth leaves. J Environ Manag 152:99-108

Hamilton MA, Russo RC, Thurston RV (1977) Trimmed SpearmanKarber method for estimating median lethal concentrations in toxicity bioassays. Environ Sci Technol 11:714-718

Harisha S, Keshavayya J, Swamy BEK, Vishwanath CC (2017) Synthesis, characterization and electrochemical studies of azo dyes derived from barbituric acid. Dyes Pigments 136:742-753

Kabbout R, Taha S (2014) Biodecolorization of textile dye biosorption of fungal biomass materials. Phys Procedia 55:437-444

Konicki W, Aleksandrzak M, Moszyn D, Mijowska E (2017) Adsorption of anionic azo-dyes from aqueous solution onto graphene oxide: equilibrium, kinetic and thermodynamic studies. J Colloid Interface Sci 496:188-200

\section{Affiliations}

\section{E. J. R. Almeida ${ }^{1}$. C. R. Corso ${ }^{1}$}

\author{
E. J. R. Almeida \\ almeidaejr@gmail.com
}

Lau YY, Wong YS, Teng TT, Morad N, Rafatullah M, Ong SA (2014) Coagulation-flocculation of azo dye Acid Orange 7 with green refined laterite soil. Chem Eng J 246:383-390

Liwarska-Bizukojc E, Miksch K, Malachowska-Jutsz A, Kalka J (2005) Acute toxicity and genotoxicity of five selected anionic and nonionic surfactants. Chemosphere 58:1249-1253

Mahmoud MS, Mostafa MK, Mohamed SA, Sobhy NA, Nasr M (2017) Bioremediation of red azo dye from aqueous solutions by Aspergillus niger strain isolated from textile wastewater. J Environ Chem Eng 05:547-554

Marcanti-Contato I, Corso CR, Oliveira JE (1997) Induction of physical paramorfogenesis in Aspergillus sp. Microbiol J 28:65-67

Mittal A, Thakur V, Gajbe V (2013) Adsorptive removal of toxic azo dyes Amido Black 10B by hen feather. Environ Sci Pollut Res 20:260-269

Olukanni OD, Osuntoki AA, Kalyani DC, Gbenle GO, Govindwar SP (2010) Decolorization and biodegradation of Reactive Blue 13 by Proteous mirabilis LAG. J Hazard Mater 184:290-298

Pachhade K, Sandhya S, Swaminathan K (2009) Ozonation of reactive dye Procion Red MX-5B catalyzed by metal ions. J Hazard Mater 167:313-318

Palácio SM, Espinoza-Quiñones FR, Módenes AN, Oliveira CC, Borba FH, Silva FG Jr (2009) Toxicity assessment from electro-coagulation treated-textile dye wastewater. J Hazard Mater 172:330-337

Platte EB, Amigo AA, Oliveira FF, Ribeiro GF (2002) Toxicity and biodegradability assessments of fluorene R2 (fluorescein). Technical communication. Research and Development Center Leopoldo A, Miguez Mello

Rawat D, Sharma RS, Karmakar S, Arora LS, Mishra V (2018) Ecotoxic potential of a presumably non-toxic azo dye. Ecotox Environ Safe 148:528-837

Rosales E, Meijide J, Tavares T, Pazos M, Sanromán MA (2016) Grapefruit peelings as a promising biosorbent for the removal of leather dyes and hexavalent chromium. Process Saf Environ Prot 101:61-71

Sen SK, Raut S, Bandyopadhyay P, Raut S (2016) Fungal decolouration and degradation of azo dyes: a review. Fungal Biol Rev 30:112-133

Song L, Shao Y, Ning S, Tan L (2017) Performance of a newly isolated salt-tolerant yeast strain Pichia occidentalis G1 for degrading and detoxifying azo dyes. Bioresource Technol 233:21-29

Vitor V, Corso CR (2008) Decolorization of textile dye by Candida albicans isolated from industrial effluents. J Ind Microbiol Biotechnol 35:1353-1357

Wang C, Boithias L, Ning Z, Han Y, Sauvage S, Sánchez-Pérez JM, Kuramochi K, Hatano R (2017a) Comparison of Langmuir and Freundlich adsorption equations within the SWAT-K model for assessing potassium environmental losses at basin scale. Agric Water Manag 180:205-211

Wang W, Huang G, An C, Xin X, Zhang T, Liu X (2017b) Transport behaviors of anionic azo dyes at interface between surfactantmodified flax shives and aqueous solution: synchrotron infrared and adsorption studies. Appl Surf Sci 405:119-128

Zhang Y, Huang G, An C, Xin X, Liu X, Raman M, Yao Y, Wang W, Doble $M$ (2017) Transport of anionic azo dyes from aqueous solution to gemini surfactant-modified wheat bran: synchrotron infrared, molecular interaction and adsorption studies. Sci Total Environ 595:723-732
1 Departamento de Bioquímica e Microbiologia, Instituto de Biociências, UNESP - Universidade Estadual de São Paulo "Júlio de Mesquita filho", Avenida 24-A, no 1515, Rio Claro, SP 13506-900, Brazil 